\title{
Failure of salmeterol to inhibit circulating white cell responses and bronchoconstriction induced by platelet activating factor
}

\author{
Joanne Spring, Stephen R Johnston, Jim Seale, Philip W Ind
}

\begin{abstract}
Background Platelet activating factor (PAF) is a potent mediator of inflammation. Inhalation of PAF causes acute bronchoconstriction and a transient fall in white blood cell count in humans. Salmeterol inhibits pulmonary inflammation induced by PAF in guinea pigs.

Methods The effect of salmeterol on effects induced by PAF was investigated in eight normal subjects who inhaled salmeterol (50 $\mu \mathrm{g})$ twice daily or a matched placebo for one week before challenge with PAF. Blood samples were taken from a forearm catheter for total white cell and neutrophil counts before and for 30 minutes after administration of PAF $(48 \mu \mathrm{g})$ through a Mefar dosimeter. Blood films were stained for unsegmented neutrophils before and after treatment with PAF on a placebo day.
\end{abstract}

Results Mean baseline total white cell counts and neutrophil counts did not differ on the two days. Mean baseline sGaw was significantly higher after inhaled salmeterol $(1.84(95 \%$ Cl $1.45-$ 2.23) $\left.\mathrm{s}^{-1} \mathrm{kPa}^{-1}\right)$ than after placebo $(1 \cdot 53$ (1.24-1.82)). After placebo mean total white cell counts, neutrophil counts, and sGaw were reduced to 60 (43-78)\%, 39 (14$64) \%$, and 82 (71-93)\% of baseline respectively five minutes after inhaled PAF. After salmeterol treatment mean reductions five minutes after inhaled PAF were $59(45-73) \%, 40(19-61) \%$, and 82 (71-93)\% of baseline respectively. At 30 minutes after treatment with PAF the neutrophil count rebounded to $143(82-204) \%$ of baseline after placebo and to 127 (93$161) \%$ after inhaled salmeterol. There was no significant difference in the percentage of immature neutrophils before and after treatment with PAF (2.0 (0.5$2 \cdot 6) \%$ compared with $3.9(2 \cdot 2-5 \cdot 6) \%$.

Conclusions Treatment with salmeterol did not inhibit reduction in total white cell count or neutrophil count, rebound neutrophilia, acute bronchoconstriction, or transient flushing after inhalation of PAF. These results conflict with the inhibitory effect of salmeterol on lung inflammation in guinea pigs but are consistent with the lack of effect of salbutamol in humans. Salmeterol does not have an anti-PAF effect in vivo in humans.

\section{(Thorax 1992;47:948-951)}

Salmeterol is a long acting selective $\beta_{2}$ agonist with significant anti-inflammatory activity both in vitro and in vivo in animal models. It is a potent inhibitor in vitro of the release of inflammatory mediators such as histamine, leukotrienes $\mathrm{C}_{4}$ and $\mathrm{D}_{4}$, and prostaglandin $\mathrm{D}_{2}$ from sensitised lung fragments challenged with antigen. ${ }^{1}$ It also inhibits release of leukotriene $\mathrm{B}_{4}$ from human neutrophils at at a significantly lower concentration than isoprenaline or salbutamol. ${ }^{2}$ In vivo, neutrophil accumulation induced in guinea pig lung by lipopolysaccharide was inhibited by salmeterol. ${ }^{3}$ Stimulation of influx of inflammatory cells into guinea pig skin by zymosan was prevented by local and oral administration of salmeterol. ${ }^{2}$ Accumulation of eosinophils induced by platelet activating factor (PAF) in guinea pig lung was also inhibited by pretreatment with salmeterol. ${ }^{3}$ In human subjects salmeterol induced inhibition of early and late phase bronchoconstriction and increase in non-specific bronchial responsiveness following allergen challenge has been quoted as evidence of an anti-inflammatory effect. ${ }^{4}$

PAF is a potent mediator of inflammation and has the ability to cause microvascular leakage, neutrophil and eosinophil activation, and bronchoconstriction. This has led to PAF being implicated in the pathogenesis of asthma. ${ }^{5}$ Non-specific bronchial hyperresponsiveness also occurred in some $e^{6-9}$ but not all human subjects ${ }^{10-11}$ after inhaled PAF. The peripheral neutrophil count was reduced transiently after inhalation of PAF in normal and asthmatic subjects and was followed by rebound neutrophilia. ${ }^{7812}$ We have recently described pulmonary sequestration of indiumlabelled neutrophils after inhalation of PAF, but not after equivalent bronchoconstriction induced by methacholine in normal subjects. ${ }^{12}$ In a recent study in normal subjects salbutamol had a partial inhibitory effect on bronchoconstriction induced by PAF but had no effects on changes in circulating white cell number. ${ }^{8}$

The aim of the present study was to investigate whether salmeterol could modulate the inflammatory effects of inhaled PAF in human subjects as it did in guinea pigs. Our hypothesis

Division of
Respiratory Medicine,
Department of
Medicine, Royal
Postgraduate Medical
School,
Hammersmith
Hospital, Ducane
Road,
London W12 oHS
J Spring
S R Johnson
J Seale
P W Ind
Reprint requests to:
Dr P W Ind
Received 19 November 1991
Returned to authors
11 March 1992
Revised version received
23 March 1992
Accepted 14 April 1992


was that changes in circulating white cell numbers reflect changes in white cells in tissues, particularly the lung. We examined changes in circulating peripheral blood cells and also effects on airways in normal subjects.

\section{Methods}

SUBJECTS

Two normal female and six normal male volunteers from hospital and laboratory staff were studied. None of the subjects had any history of asthma. None had suffered any recent chest infection and no subjects were taking any medication. None were atopic and one subject was an ex-smoker. Mean age was 32 (range 24 44) years. Each subject gave written informed consent to participate in the study, which was approved by the Hammersmith Hospital ethics committee.

\section{STUDY DESIGN}

Each subject was studied in a randomised, double blind, placebo controlled manner on two separate occasions separated by at least three weeks. Subjects inhaled salmeterol (50 $\mu \mathrm{g}$ ) or matched placebo through a diskhaler twice daily for one week before visiting the laboratory. The last dose of salmeterol or placebo was inhaled on the study day two hours before challenge with PAF. Airway calibre was recorded by measurement of specific airways conductance (sGaw), as a mean of six determinations, in a computerised constant volume body plethysmograph. ${ }^{13}$ Forced expiratory volume in one second $\left(\mathrm{FEV}_{1}\right)$ was measured as the best of three manoeuvres with a wedge spirometer (Vitalograph, Buckingham, UK).

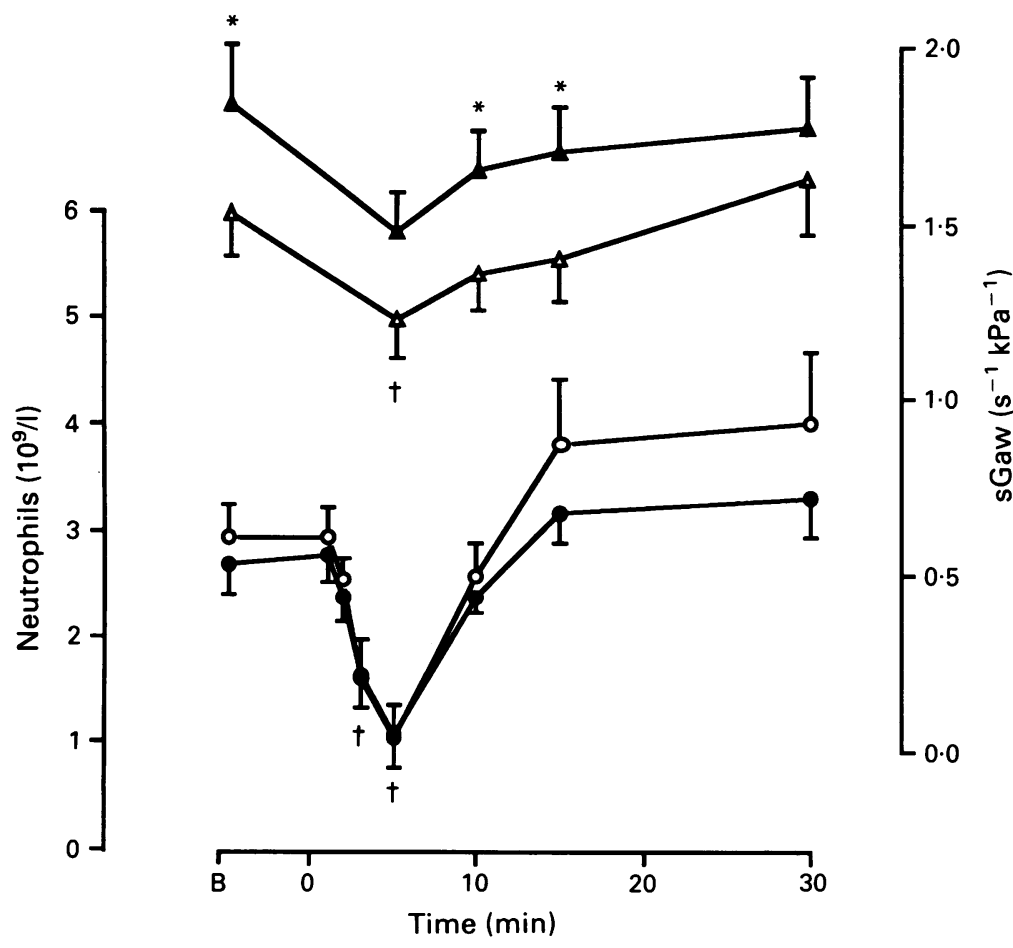

Neutrophil count after salmeterol (O) and placebo (O) and specific airways conductance (sGaw) after salmeterol $(\Delta)$ and placebo $(\triangle)$ before and after challenge with $P A F$. Error bars represent $S E \cdot B$ represents baseline values. $P A F$ was administered at time $0 . \star$ Significant difference between salmeterol and placebo administered at time $0 . \star$ Significant difference between salmeterol and
$(p<0.05) ; \dagger$ significant differences from baseline for both salmeterol and placebo $(p<0.05)$.
Blood samples were drawn from a cannula placed in a forearm vein for total white blood cell and neutrophil counts before and for 30 minutes after administration of PAF.

\section{PAF INHALATION CHALLENGE}

PAF (Bachem Inc, California) was dissolved and stored in aliquots at a concentration of 10 $\mathrm{mg} / \mathrm{ml}$ in $100 \%$ ethanol at $-77^{\circ} \mathrm{C}$. On the morning of each study PAF was diluted to 2 $\mathrm{mg} / \mathrm{ml}$ in $0.9 \%$ saline containing heat treated human serum albumin at a final concentration of $0.04 \%$. The PAF aerosol was delivered from a Mefar dosimeter (Brescia, Italy) driven by compressed air at a pressure of $1.5 \mathrm{~kg} / \mathrm{m}^{2}$, with a one second actuation time and five seconds between puffs. Output was measured as $12 \mu \mathrm{l}$ for each puff. Each subject received two puffs (48 $\mu \mathrm{g}$ PAF). Airways response to PAF was measured as changes in sGaw and in $\mathrm{FEV}_{1}$. Measurements were made before inhalation of PAF (baseline) and seven, 12, 17, and 32 minutes after inhalation of PAF.

\section{MEASUREMENT OF CIRCULATING CELLS}

Duplicate venous blood samples $(2 \times 2 \mathrm{ml})$ were collected five minutes before and one, two, three, five, 10, 15, and 30 minutes after inhalation of PAF for determination of total white blood cell and neutrophil counts. Cell counts, including total and differential leucocyte counts and platelet counts, were determined in each of the paired samples by automatic analyser (Sysmex E500) and mean values were recorded. Coefficients of variation were $1.8 \%$ for total leucocyte counts and $6 \%$ for neutrophil counts.

An independent observer, unaware of the patient protocol, examined blood films prepared and stained by a routine May-Grünwald Giemsa method to look for evidence of newly released immature neutrophils. Films from samples collected at -5 and +30 minutes on a placebo day were coded and examined in random order. A manual differential count was performed on 100 white blood cells on the two films from each subject. Particular care was taken to distinguish between mature segmented neutrophils and less mature unsegmented band forms.

DATA ANALYSIS

Results were expressed as means (95\% confidence intervals $(95 \% \mathrm{CI})$ ). Analysis of variance (ANOVA) of repeated measures for sGaw and $F E V_{1}$, neutrophil, and white blood cell count was used to determine the effect of salmeterol compared with placebo. Wilcoxon's rank sum test was used to determine significance at specific time points. $p$ values $<0.05$ were considered significant.

\section{Results}

All subjects noted transient facial flushing, cough, and minor chest tightness. Conjunctival injection was seen in every subject one to two minutes after inhalation of PAF. Previous treatment with salmeterol did not prevent these symptoms. 


\section{AIRWAY CHANGES}

Mean baseline sGaw was significantly higher ( $p$ $<0.01)$ after treatment with salmeterol $(1.8$ $\left.(1 \cdot 4-2 \cdot 2) \mathrm{s}^{-1} \mathrm{kPa}^{-1}\right)$ compared with placebo (1.5 $(1 \cdot 2-1 \cdot 8) \mathrm{s}^{-1} \mathrm{kPa}^{-1}$ ) (figure). Baseline $\mathrm{FEV}_{1}$ after treatment with salmeterol was higher but did not differ significantly from that after placebo. There was some variation in airway response to PAF in the different subjects. One subject showed no significant change in sGaw after PAF on either study day. Values for sGaw after treatment with salmeterol were significantly higher than after placebo 10 and 15 minutes after inhaled PAF ( $p<0.05$ for both), although the percentage baseline values did not differ. After salmeterol, inhalation of PAF caused a maximum reduction in $\mathrm{sGaw}$ at five minutes to $82(74-90) \%$ of the baseline value. A remarkably similar fall in sGaw after inhaled PAF occurred with placebo to 82 (71-93)\% of baseline (figure). These values were both significantly different from baseline $(p<0.001$ and $p<0.01$ respectively). Generally, changes in $F E V_{1}$ were smaller than those in sGaw. $F E V_{1}$ five minutes after inhaled PAF fell to 93 (90$96) \%$ of baseline on the day of salmeterol treatment and 91 (87-95)\% of baseline on the day of placebo $(p=0 \cdot 08)$.

\section{EFFECT ON CIRCULATING CELLS}

Neither total peripheral white cell counts nor neutrophil counts differed significantly after one week of treatment with salmeterol or placebo. Baseline peripheral white cell counts and neutrophil counts were $5 \cdot 0(4 \cdot 1-5 \cdot 8) \times 10^{9}$ $1^{-1}$ and $2.7(2 \cdot 0-3.4) \times 10^{9} \mathrm{1}^{-1}$ on salmeterol treatment and 5.3(4.4-6.2) $\times 10^{9} \mathrm{l}^{-1}$ and $3(2 \cdot 2$ 3.7) $\times 10^{9} 1^{-1}$ on placebo. After inhaled PAF, changes in total white cell count mirrored changes in neutrophil count in every instance. When compared with placebo salmeterol had no effect on neutrophil count at any time point (figure). Three minutes after inhalation of PAF the neutrophil count decreased significantly from baseline. On the placebo day the neutrophil count fell to $1.7(0.8-2.5) 10^{9} 1^{-1}(\mathrm{p}<0.02)$ and on the salmeterol treatment day to $1.7(1.0$ $2.4) 10^{9} \mathrm{l}^{-1}(\mathrm{p}<0.01)$. The mean maximum reduction in circulating neutrophils occurred five minutes after inhaled PAF, to $40(19-61) \%$ of baseline $(p<0.001)$ with salmeterol treatment and $39(14-64) \%$ baseline $(\mathrm{p}<0.001)$ with placebo. Neutrophil count rebounded to $127(93-161) \%$ of baseline 30 minutes after inhaled PAF with salmeterol treatment and to $143(82-204) \%$ on placebo. Salmeterol did not significantly affect the transient neutropenia or rebound neutrophilia after inhaled PAF.

Circulating lymphocyte and platelet counts did not change significantly with salmeterol treatment compared with placebo or after inhaled PAF on either study day. Before inhalation of PAF band neutrophils represented a mean $2.0(0.5-2 \cdot 6) \%$ of the total neutrophil count and $3.9(2 \cdot 2-5 \cdot 6) \%$ at 30 minutes after PAF inhalation. There was no significant change $(p=0 \cdot 10)$ in the number of immature neutrophils before or after inhalation of PAF. Thus the slight rise in total neutrophils was not due to significant release of immature granulocytes from the bone marrow.

\section{Discussion}

We have confirmed previous findings that inhaled PAF causes transient bronchoconstriction and changes in neutrophil count in human subjects. Salmeterol at a standard clinical dose $(50 \mu \mathrm{g})$ inhaled twice daily for one week did not significantly modify the reduction in neutrophil count after inhaled PAF or the subsequent rebound neutrophilia. Salmeterol caused baseline bronchodilatation, confirming compliance, but did not prevent the bronchoconstrictor response to inhaled PAF compared with placebo.

This study precisely defines the time course of the effect of PAF on neutrophils. The first reduction was seen at three minutes with the maximal effect at five minutes as previously documented. ${ }^{7811}$ Salmeterol had no effect on the time course, or on the degree of leucopenia, or on subsequent rebound neutrophilia compared with placebo, and this was consistent with a previous study of a single dose of inhaled salbutamol. $^{8}$

The lack of effect on circulating neutrophils shown here suggests that salmeterol is unlikely to modulate pulmonary sequestration of neutrophils $^{12}$ although this has not been studied directly. This conflicts with the inhibitory effect of salmeterol on migration of neutrophils into guinea pig lung ${ }^{3}$ and skin ${ }^{2}$ and pulmonary accumulation of eosinophils induced by PAF. ${ }^{3}$ The hypothesis that changes in pulmonary white cell numbers are adequately mirrored by changes in the circulation has not been tested but radiation dose prevented examination in a study of similar design to this. ${ }^{12}$ It may be possible to pursue this with prostacyclin, which has been suggested to modify circulating white cell changes after inhalation of PAF. ${ }^{14}$

The mechanism of bronchoconstriction induced by PAF in humans remains unknown. Cholinergic nervous pathways are not involved. ${ }^{7}$ The role of histamine is unclear as chlorpheniramine produced partial inhibition ${ }^{7}$ whereas other studies with different $\mathrm{H}_{1}$ blockers had no effect. ${ }^{1516}$ In animals, secondary mediator release after treatment with PAF involves leukotriene and cyclo-oxygenase products including thromboxane $\mathrm{A}_{2}{ }^{17}$ In humans, thromboxane has at most a minor role. $^{71819}$ Major cysteinyl leukotriene release was found, however, after inhaled $\mathrm{PAF}^{19}$ and selective leukotriene $\mathrm{C}_{4}$ and $\mathrm{D}_{4}$ antagonists inhibited bronchoconstriction induced by PAF. $^{2021}$ Salmeterol is effective in blocking release of leukotrienes from human lungs in vitro. ${ }^{2}$ It is therefore all the more surprising that in this study salmeterol did not inhibit airway narrowing induced by PAF.

It is difficult to relate the standard clinical dose of salmeterol used here with that which was effective in vitro, ${ }^{12}$ but in guinea pigs in vivo the bronchodilator concentration of salmeterol $(0.1 \mathrm{mM})$ also inhibited neutrophil accumulation induced by lipopolysaccharide 
and accumulation of eosinophils induced by PAF. ${ }^{23}$

Minimum sGaw after challenge was significantly higher after treatment with salmeterol than after placebo but the percentage reduction was unaffected (figure). In a previous study a single dose of salbutamol $(200 \mu \mathrm{g})$ partially inhibited bronchoconstriction induced by PAF, measured as partial flow at $30 \%$ of vital capacity.

A standard clinical bronchodilator dose of salmeterol was used that would have been expected to block contraction of bronchial smooth muscle. The lack of protective effect of salmeterol suggests that airway narrowing induced by PAF may be due to airway oedema as PAF is known to be a potent mediator of microvascular leakage. ${ }^{5}$ This would also be consistent with the findings that acute protection by salbutamol was much less for PAF than equivalent bronchoconstriction induced by methacholine. ${ }^{8}$

Salmeterol produced bronchodilatation but did not inhibit PAF induced airway narrowing, cough, vasodilator effects, or neutrophil changes. These results conflict with the inhibitory effect of salmeterol on lung inflammation in guinea pigs but are consistent with the lack of effect of salbutamol in humans. Any antiinflammatory effect of salmeterol is therefore unlikely to be mediated through PAF. The only evidence of an anti-inflammatory effect of salmeterol in vivo in humans comes from the inhibition of the late phase reaction to allergen in atopic asthmatic patients. ${ }^{4}$ There has been some discussion of the significance of these results ${ }^{22}$ in the light of baseline bronchodilatation of the type seen in our study. No effect of salmeterol on inflammatory indicators of allergen response was found. ${ }^{23}$ We have no evidence to support an anti-inflammatory effect of salmeterol.

1 Butchers PR, Cousins SA, Vardey CJ. Salmeterol; A potent and long acting inhibitor of the release of inflammatory Pharmacol 1987;92:745P

2 Johnson $M$. The pharmacology of salmeterol. Lung 1990(suppl):115-9.
3 Whelan CJ, Johnson M. Salmeterol inhibits granulocyte accumulation in guinea-pig lung. $\mathrm{Br} J$ Pharmacol 1991;102:176P.

4 Twentyman OP, Finnerty JP, Harris A, Palmer J, Holgate ST. Protection against allergen-induced asthma by salmeterol. Lancet 1990;336:1338-42.

5 Barnes PJ, Chung KF, Page C. Platelet-activating factor as a mediator of allergic disease. J Allergy Clin Immunol 1988;81:919-33.

6 Cuss F, Dixon C, Barnes P. Effects of inhaled platelet activating factor on pulmonary function and bronchial responsiveness in man. Lancet 1986;ii:189-92.

7 Smith LJ, Rubin AH, Patterson R. Mechanism of platelet activating factor-induced bronchoconstriction in humans. Am Rev Respir Dis 1988;137:1015-9.

8 Chung KF, Dent G, Barnes PJ. Effects of salbutamol on bronchoconstriction, bronchial hyperresponsiveness, and leucocyte responses induced by platelet activating factor in man. Thorax 1989;44:102-7.

9 Wardlaw AJ, Chung KF, Moqbel R, MacDonald AJ, Hartnell A, McCusker M, et al. Effects of inhaled PAF in humans on circulating and bronchoalveolar lavage fluid neutrophils. Am Rev Respir Dis 1990;141:386-92.

10 Lai CKW, Jenkins JR, Polosa R, Holgate ST. Inhaled PAF fails to induce airway hyperresponsiveness to methafails to induce airway hyperresponsiveness to metha-
choline in normal human subjects. $J$ Appl Physiol 1990;68:919-26.

11 Spencer DA, Green SE, Evans JM, Piper PJ, Costello JF. Platelet activating factor does not cause a reproducible increase in bronchial responsiveness in normal man. Clin Exp Allergy 1990;20:525-32.

12 Tam FWK, Clague J, Dixon CMS, Stuttle AWJ, Henderson BL, Peters AM, et al. Neutrophil sequestration in normal human lung after inhalation of platelet activating factor (PAF). Thorax 1990;45:791P.

13 Chowienczyk PJ, Rees PJ, Payne J, Clark TJH. A new method for computer assisted determination of airways resistance. J Appl Physiol 1981;50:672-8.

14 Lammers J-JW, Kioumis I, McCusker M, Roberts NM Nichol GM, Barnes PJ, et al. Effects of Prostacyclin on bronchodilatation and neutropaenia induced by inhaled pronchodilatation and neutropaenia induced by inhaled platelet activating

15 Chung KF, Minette P, McCusker M, Barnes PJ. Ketotifen inhibits the cutaneous but not the airway responses to platelet activating factor in man. J Allergy Clin Immunol 1988;81:1192-8.

16 Ghosh KF, Rafferty P, Patel KR. Effect of cetrizine on platelet factor induced bronchoconstriction in patients with asthma. Thorax 1990;45:797.

17 Jancar S, Theriault P, Lauziere M, Braquet P, Sirois P. PAF-induced release of spasmogens from guinea-pig lungs. Br J Pharmacol 1989;96:153-62.

18 Stenton SC, Ward C, Duddridge M, et al. The actions of GR3219B, a thromboxane antagonist, on PAF-induced bronchoconstriction and bronchial hyperresponsiveness. Clin Exp Allergy 1990;20:211-7.

19 Taylor IK, Ward PS, Dollery CT, Fuller RW. Inhaled PAF stimulates leukotriene and thromboxane $A_{2}$ production in humans. J Appl Physiol 1991;71:1396-402.

20 Spencer DA, Evans JM, Green SE, Piper PJ, Costello JF. Participation of the cysteinyl leukotrienes in the acute bronchoconstrictor response to platelet activating factor in man. Thorax 1991;46:441-5.

21 Kidney JC, Ridge R, Chung KF, Barnes PJ. Inhibition of PAF-induced bronchoconstriction by the oral leukotriene D4 receptor antagonist ICI204.219 in normal subjects. Am Rev Respir Dis 1991;143:A811.

22 Rogers TR, Higgins $\mathrm{K}$, Morice A. $\mathrm{B}_{2}$ agonists in asthma (letter). Lancet 1991;337:46.

23 O'Shaughnessy K, Taylor IK, Fuller RW. $\beta_{2}$ agonists in asthma (letter). Lancet 1991;337:45-6. 